\title{
Study of mechanical properties and absorption behaviour of coconut shell powder-epoxy composites
}

\author{
Alok Singh ${ }^{1}$, Savita Singh ${ }^{1}$, Aditya Kumar ${ }^{2}$ \\ ${ }^{1}$ Department of Physics, PSIT College of Engineering, Kanpur-208020, Uttar Pradesh, India \\ ${ }^{2}$ Department of Mechanical Engineering, PSIT College of Engineering, Kanpur-208020, Uttar Pradesh, India
}

\section{Email address:}

dr.singhalok@gmail.com (A. Singh)

\section{To cite this article:}

Alok Singh, Savita Singh, Aditya Kumar. Study of Mechanical Properties and Absorption Behaviour of Coconut Shell Powder-Epoxy Composites. International Journal of Materials Science and Applications. Vol. 2, No. 5, 2013, pp. 157-161.

doi: $10.11648 /$ j.ijmsa.20130205.12

\begin{abstract}
The present paper reports to develop a polymer matrix composite (Epoxy- resin) using coconut shell powder (CSP) in different particle size and reinforcing in different volume and evaluate its tensile strength, flexural property and hydrophilic behavior along with engineering application of resulting composites.
\end{abstract}

Keywords: Coconut Shell Powder (CSP), Polymer Matrix Composite, Tensile, Flexural

\section{Introduction}

The interest in natural fiber-reinforced polymer composite materials is rapidly growing both in terms of their industrial applications and fundamental research. They are renewable, cheap, completely or partially recyclable, and biodegradable. Plants, such as flax, cotton, hemp, jute, sisal, kenaf, pineapple, ramie, bamboo, banana, etc., as well as wood, used from time immemorial as a source of lignocellulosic fibers, are more and more often applied as the reinforcement of composites. Their availability, renewability, low density, and price as well as satisfactory mechanical properties make them an attractive ecological alternative to glass, carbon and man-made fibers used for the manufacturing of composites. The natural fiber-containing composites are more environmentally friendly, and are used in transportation (automobiles, railway coaches, aerospace), military applications, building and construction industries (ceiling paneling, partition boards), packaging, consumer products, etc [1].

Coconut shells are available in abundance in tropical countries as a waste product after consumption of coconut water and meat. Such abundance can fulfill the demand of filler based composites while reducing waste. Procurement and processing of coconut shell powder is cost effective than other artificial fillers.

Flexural and tensile properties of coconut shell reinforced polyester composite are studied by S.Husseinyah and $\mathrm{M}$. Mustapha [2-7]. They prepared the composite by using coconut shell powder as filler $(0,15,30,45$, and $60 \%$ by weight $)$. Their result indicated better flexural and tensile strength of polyester composites compared to un-reinforced samples.

The morphology and mechanical properties of coconut shell reinforced polyethylene composite have been evaluated to establish the possibility of using it as a new material for engineering applications. Coconut shell reinforced composites was prepared by compacting low density polyethylene matrix with $5 \%-25 \%$ fractional volume of coconut shell particles and the effect of particles on the mechanical properties of the composite produced was investigated. The result shows that the hardness of the composites increases with increase in coconut shell content though the tensile strength, modulus of elasticity, impact energy and ductility of the composite decreases with increase in the particle content [8].

Han-Seung Yang et al [9] reported that the tensile strengths of the bio-composites decrease slightly as the filler loading increased, however the composites retained an acceptable level of strength. As the filler loading increases, the poor interfacial bonding between the filler and matrix polymer caused the tensile strength and Izod impact strength of the composites to be reduced and this poor interfacial bonding results an increase in the number of micro voids causing increased water absorption. With the addition of compatibilizing agent, the interfacial bonding between the filler and the matrix polymer was greatly improved, resulting in improved dimensional stabilities and water absorption behavior. 
The present paper reports to prepare the coconut shell powder in different particle size and reinforcing in different volume and evaluate its tensile strength, flexural property and hydrophilic behavior along with engineering application of resulting composites.

\section{Experimental Procedure}

Materials used in this experimental work are Epoxy resin, Hardener and Coconut shell powder. Epoxy resin Moditite EL 301 is a thermosetting epoxy resin of medium viscosity supplied by Ruchi Organics Limited, Kanpur, Uttarpradesh, India having outstanding properties as the matrix material like excellent adhesion to different materials, high resistance to chemical and atmospheric attack, high dimensional stability, excellent mechanical properties, nontoxic nature and negligible shrinkage. Hardener MH-933 is used to harden matrix material. The chemical composition of coconut shell powder consists of Lignin (29.4\%), Pentosans $(27.7 \%)$, Cellulose (26.6\%), Moisture (8\%), Solvent Extractives(4.2\%), Uronic Anhydrides(3.5\%) and Ash $(0.6 \%)$. The cleaned coconut shells were crushed into small pieces by using hammer. These small pieces then converted into powder by using hammer. The collected powder was then sieved to different mesh sizes. For discriminating different CSP particle size about $1000 \mathrm{~g}$ of CSP was put over the sieve shaker and shaken it for $20 \mathrm{~min}$ in shaker shown in Fig.1 (a). The sieves were arranged in the following order - crushed CSP, 600 micron (ASTM no. 8), 425 micron (ASTM no. 7), 300 micron (ASTM no. 6), 212 micron (ASTM no. 5) and then dust collector.

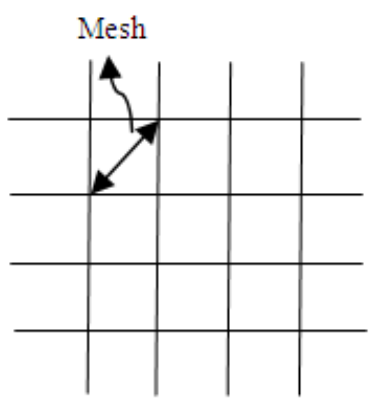

(a)

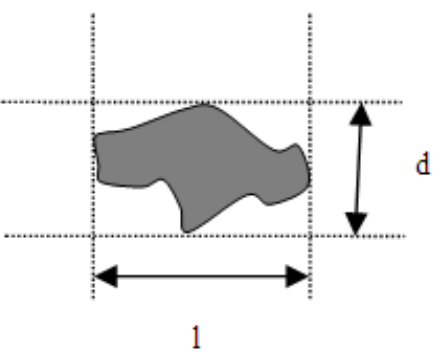

(b)
Figure1. (a) Mesh of Sieves (b) Irregular shape Shell particle

Fig.1 (b) illustrates an irregular shape of CSP particle in which two dimensions $\mathrm{d}$ and 1 , where, 1 is the larger dimension and $\mathrm{d}$ is the smaller one. The following observations are reported,

$$
1=1.25 \mathrm{~d}
$$

1. The CSP particle passes through a mesh when smaller dimension $(\mathrm{d})<$ Mesh size.

2. The CSP particle does not pass through a mesh if smaller dimension $(\mathrm{d})>$ Mesh size.

The CSP particle size as per ASTM is given in table 1 .
Table1. CSP Particle Size

\begin{tabular}{cccc}
\hline Sample No. & $\begin{array}{c}\text { ASTM } \\
\text { Number }\end{array}$ & \multicolumn{2}{c}{ Size range (Microns) } \\
Maximum & Size & Minimum Size \\
\hline $\mathbf{1}$ & 8 & 850 & 600 \\
$\mathbf{2}$ & 7 & 600 & 425 \\
$\mathbf{3}$ & 6 & 425 & 300 \\
$\mathbf{4}$ & 5 & 300 & 212 \\
\hline
\end{tabular}

Filler powder is obtained by mixing the various particle sizes in the ratio indicated by table 2 .

Table2. Mixing ratio

\begin{tabular}{ccc}
\hline S. No. & $\begin{array}{c}\text { Particle Size } \\
\text { (Microns) }\end{array}$ & Percentage \\
\hline $\mathbf{1}$ & $850>$ size $>600$ & $30 \%$ \\
$\mathbf{2}$ & $600>$ size $>425$ & $13 \%$ \\
$\mathbf{3}$ & $425>$ size $>300$ & $12 \%$ \\
$\mathbf{4}$ & $300>$ size $>212$ & $15 \%$ \\
$\mathbf{5}$ & Dust & $30 \%$ \\
\hline
\end{tabular}

The different particle sizes were chosen as illustrated in table2 for developing polymer matrix composite (Epoxy-resin) using coconut shell powder (CSP).

\subsection{Preparation of Composites}

A mold of $320 \mathrm{~mm} \times 180 \mathrm{~mm} \times 6 \mathrm{~mm}$ having base of glass and sides of wood was used for casting the composite sheets. For quick and easy removal of the composite sheet a mold release sheet was kept over glass plate. The weight percents of coconut shell powder (i.e. 20, 30 and 40 weight \%), was mixed with the matrix material consisting of epoxy resin and hardener in the ratio of 5:4. Care was taken to avoid formation of air bubbles during pouring and mixture was allowed to cure at room temperature for 24 hours. After the curing the laminate was cut into required size of various mechanical tests and water absorption test.

\subsection{Characterization of the Composites}

The theoretical density of composite material in terms of weight fraction was found from the following equation as given by Agarwal and Broutman.

$$
\rho_{\text {comp }}=\frac{1}{\left(\frac{w_{\text {csp }}}{\rho_{\text {csp }}}+\frac{w_{\text {mat }}}{\rho_{\text {mat }}}\right)}
$$

Where, ' $\mathrm{W}$ ' and ' $\rho$ ' represents the weight fraction and density respectively. The subscript comp, csp and mat stands for composite, coconut shell powder and the matrix respectively.

\subsection{Testing of Mechanical Properties of Composites}

The study of mechanical properties such as tensile strength, flexural strength of coconut shell powder 
reinforced (randomly distributed in epoxy matrix) composite have been conducted as per ASTM standard.

\subsubsection{Tensile Strength}

The tensile test was generally performed on flat composite sample. The commonly used shape for sample was the dog-bone. The length of the test specimen was 163 mm as per ASTM D638-03 shown in Fig. 2. The tensile test was performed in INSTRON 1195 testing machine shown in Fig.3. The test was performed with a cross head speed of 2 $\mathrm{mm} / \mathrm{min}$. for three samples of different CSP filled volume fraction and average value was taken for analysis.

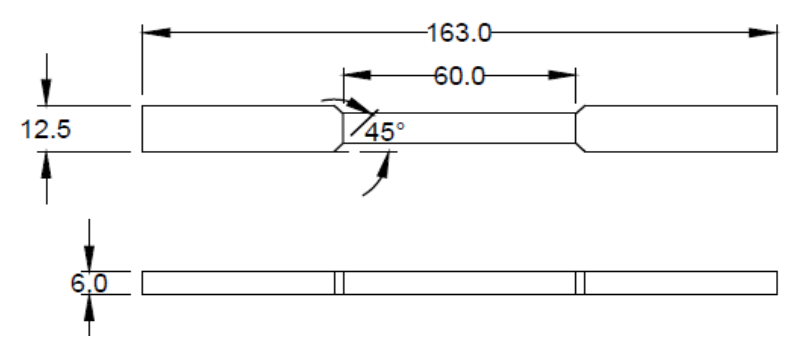

Figure2. Tensile test specimen

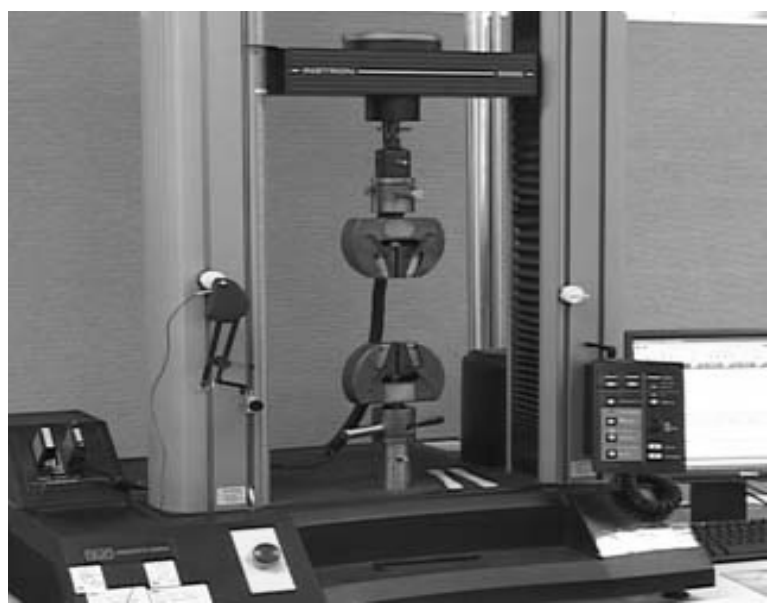

Figure3. INSTRON 1195 testing machine

\subsubsection{Flexural Testing}

Flexural test were performed using three point bending method according to ASTM D790-03 procedure shown in Fig.4. The composite samples were tested at a cross head speed of $2 \mathrm{~mm} / \mathrm{min}$, at a temperature $22^{\circ} \mathrm{C}$ and humidity $50 \%$. In each case three samples were taken and average value was recorded. The flexural stress in a three point bending test was found out by using equation as follows,

$$
\sigma_{\max }=\frac{3 \mathrm{P}_{\max }^{\mathrm{m}} \mathrm{L}}{b \mathrm{~h}^{2}}
$$

Where, $\mathrm{P}_{\max }$ is the maximum load at failure $(\mathrm{N}), \mathrm{L}$ is the span $(\mathrm{mm}), \mathrm{b}$ and $\mathrm{h}$ is the width and thickness of the specimen $(\mathrm{mm})$ respectively. The flexural modulus was calculated from the slope of the initial portion of the load-deflection curve which was found out by using equation as follows,

$$
\mathrm{E}=\frac{\mathrm{mL}}{4 \mathrm{bh}^{2}}
$$

Where, $\mathrm{m}$ is the initial slope of the load deflection curve for each stacking sequence, three specimens were tested and average result was obtained.

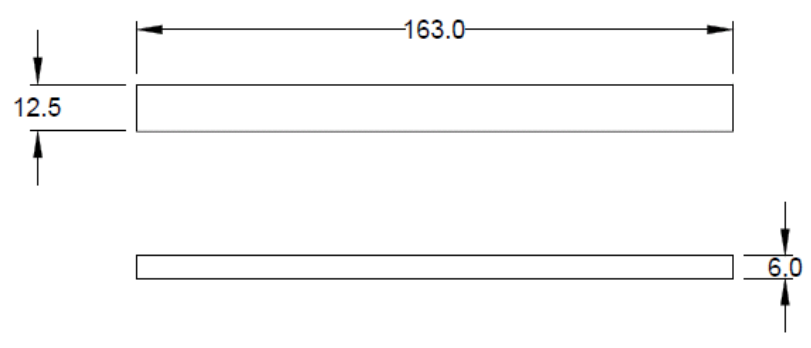

Figure4. Flexural test specimens

\subsection{Test Sample}

The test sample was in the form of a bar $76.2 \mathrm{~mm} \times 25.4 \mathrm{~mm} \times 6 \mathrm{~mm}$. It was sawed from the composite samples so as to have smoothed edges free from cracks. The cut edges smoothen by finishing with zero number emery cloth. Sawing and sand papering operation was done slowly enough, so that the material is not heated appreciably.

\subsection{Absorption Test Procedure}

Long term water immersion method was used to determine the absorption behavior of composites. The conditioned composite sample was placed in a beaker with water at $23 \pm 1^{\circ}$. At the end of 24 hours one of the sample is removed from the water at a time, all surface water wiped off with a dry cloth and weighed immediately and then replaced in the water and this procedure was repeated at every 24 hours till 7 days and the data was recorded. The percentage increase in weight was calculated to the nearest $0.01 \%$ by using equation as follows,

Increase in weight $\%=\frac{\text { Wet weight }- \text { Conditioned weight }}{\text { Condhliuned weiglı }} \times 100$

\section{Results and Discussion}

\subsection{Density}

The density of the different composites is tabulated in table 3 .

Table3. Density of composites

\begin{tabular}{ccc}
\hline S.No. & Sample & Density $\left(\mathbf{g} / \mathbf{c m}^{\mathbf{3}}\right)$ \\
\hline $\mathbf{1}$ & 20\% CSP filled composite & 1.0462 \\
$\mathbf{2}$ & 30\% CSP filled composite & 1.0532 \\
$\mathbf{3}$ & 40\% CSP filled composite & 1.0629 \\
\hline
\end{tabular}




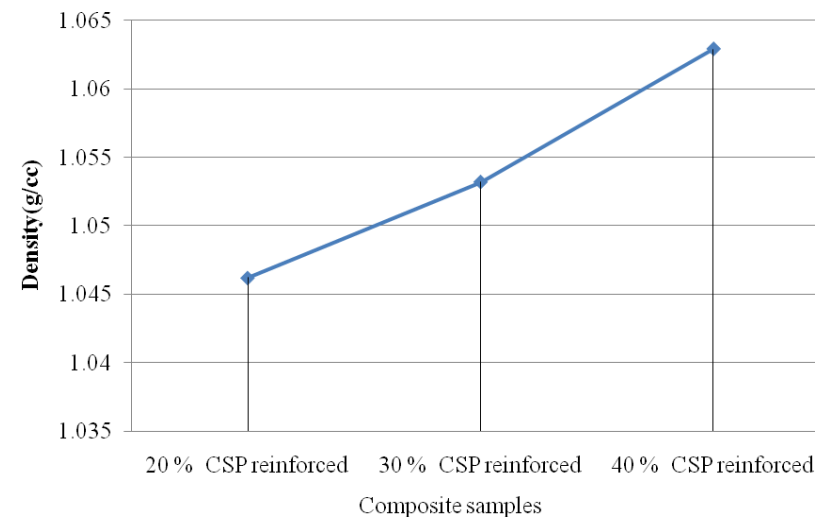

Figure5. Density curve

The density test results for various samples which are prepared by filling of CSP with different volume fraction were plotted in Fig. 5 . The density curve illustrates that, the density of the composite having $20 \%$ CSP reinforcement is less compared to others. It is also observed that an increase of reinforcing volume the corresponding density increases.

\subsection{Tensile Strength}

The tensile strength of different composite samples is obtained after testing and provided in table 4 .

Table4. Tensile strength of composites

\begin{tabular}{ccc}
\hline S.No. & Composite Samples & $\begin{array}{c}\text { Tensile Strength } \\
\text { (MPa) }\end{array}$ \\
\hline $\mathbf{1}$ & $20 \%$ CSP Filled & 19.23 \\
$\mathbf{2}$ & $30 \%$ CSP Filled & 17.05 \\
$\mathbf{3}$ & $40 \%$ CSP Filled & 14.64 \\
\hline
\end{tabular}

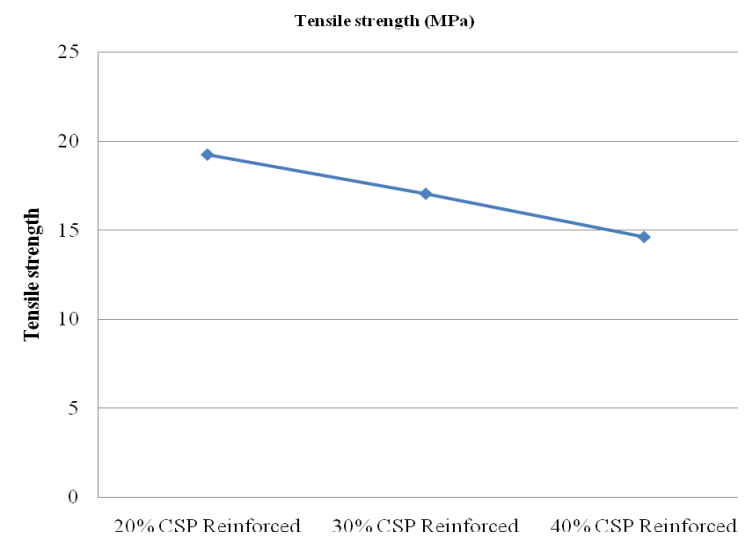

Figure6. Tensile strength curve

The tensile strength results in table 4 for various samples which are prepared with CSP filler with different volume fraction were plotted in Fig.6. The tensile curve illustrates that, the maximum tensile strength is obtained for the composite prepared with $20 \% \mathrm{CSP}$ volume fraction. It is also observed that an increase of CSP filler volume the corresponding tensile strength decreases.

\subsection{Flexural Strength}

The flexural strength of different composite samples is given in table 5 .

Table5. Flexural strength of composites

\begin{tabular}{ccc}
\hline S.No. & Composite Samples & $\begin{array}{c}\text { Flexural Strength } \\
\text { (MPa) }\end{array}$ \\
\hline $\mathbf{1}$ & $20 \%$ CSP Filled & 83.38 \\
$\mathbf{2}$ & $30 \%$ CSP Filled & 86.45 \\
$\mathbf{3}$ & $40 \%$ CSP Filled & 73.92 \\
\hline
\end{tabular}

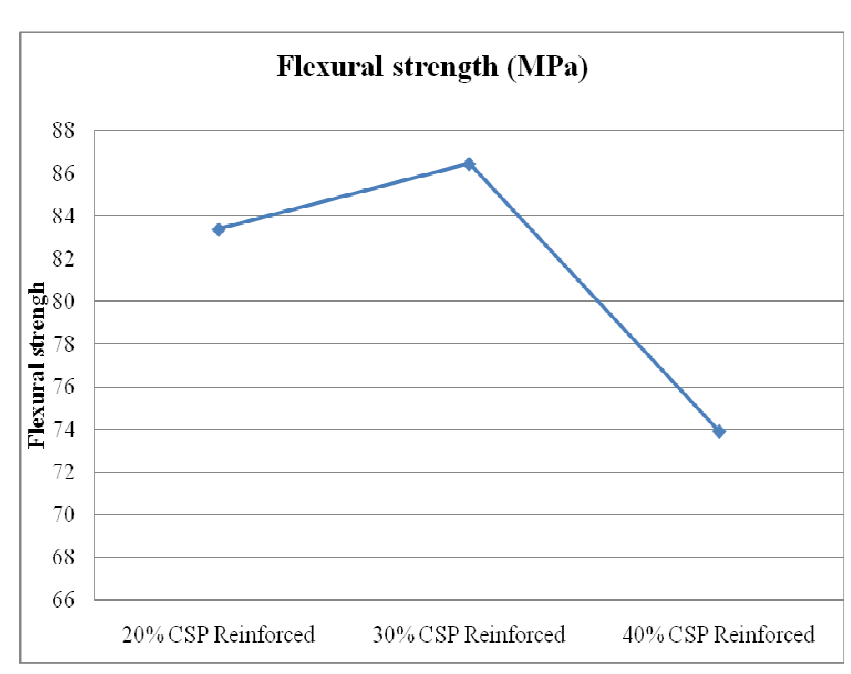

Figure7. Flexural strength curve

Fig. 7 shows the variation in flexural strength for different volume fraction of CSP reinforced composites. The flexural strength curve illustrates that, the maximum flexural strength is obtained for the composite $30 \%$ CSP filled.

\subsection{Water Absorption Behavior}

The water absorption behavior of different composite samples was observed and recorded in table 6 .

Table6. Water absorption percentage

\begin{tabular}{|c|c|c|c|c|c|c|c|}
\hline Composite & $\begin{array}{c}24 \\
\text { Hrs }\end{array}$ & $\begin{array}{c}48 \\
\text { Hrs }\end{array}$ & $\begin{array}{c}72 \\
\text { Hrs }\end{array}$ & $\begin{array}{l}96 \\
\text { Hrs }\end{array}$ & $\begin{array}{l}120 \\
\text { Hrs }\end{array}$ & $\begin{array}{l}144 \\
\text { Hrs }\end{array}$ & $\begin{array}{l}168 \\
\text { Hrs }\end{array}$ \\
\hline $\begin{array}{c}20 \% \text { CSP } \\
\text { filled }\end{array}$ & 0.75 & 0.77 & 0.88 & 1.05 & 1.16 & 1.3 & 1.66 \\
\hline $\begin{array}{c}30 \% \text { CSP } \\
\text { filled }\end{array}$ & 0.88 & 1.23 & 1.48 & 1.67 & 1.97 & 2.24 & 2.6 \\
\hline $\begin{array}{l}40 \% \text { CSP } \\
\text { filled }\end{array}$ & 1.25 & 1.49 & 1.63 & 1.84 & 2.06 & 2.38 & 2.7 \\
\hline
\end{tabular}




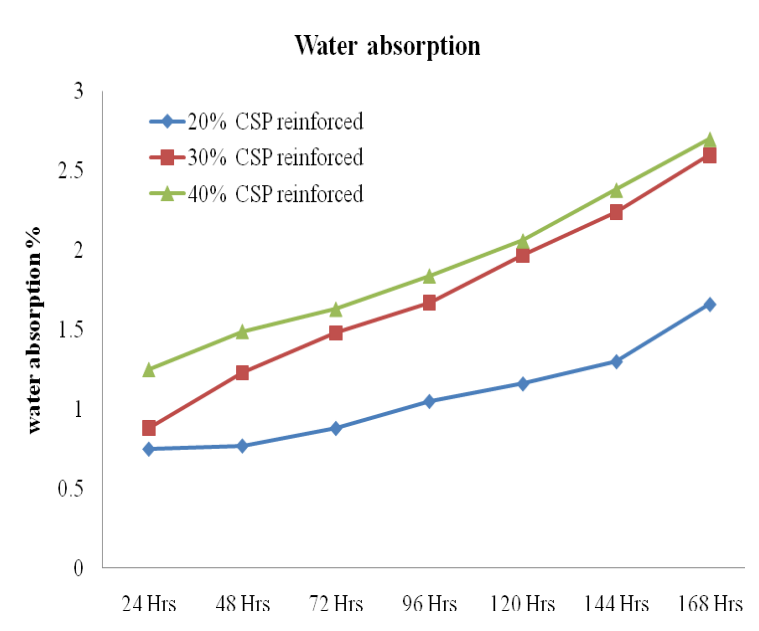

Figure8. Water absorption curve

The water absorption results for various samples which are prepared with CSP filler with different volume fraction were plotted in fig. 8 . The water absorption curve illustrates that the minimum water absorption is for the composite prepared with $20 \%$ CSP volume fraction. It is also observed that an increase of CSP filler volume the corresponding water absorption percentage increases.

\section{Conclusions}

The experimental investigation on mechanical properties viz. density, tensile strength and flexural strength of CSP epoxy composite material is greatly influenced by the CSP filled volume fraction.

The density of the composite having $20 \%$ CSP filled is less compared to others. The density curve (See Fig. 5) shows that an increase of filler volume from $20 \%$ to $30 \%$ the density increases gradually while an increase in filler volume from $30 \%$ to $40 \%$ the density increases rapidly. Thus, the rate of increase in density is maximum from $30 \%$ to $40 \%$ CSP filled composites.

The maximum tensile strength is obtained for the composite prepared with $20 \%$ CSP volume fraction. The tensile strength curve (See Fig. 6) shows an increase of filler volume the tensile strength goes on decreasing. Thus, the rate of decrease of tensile strength from $20 \%$ to $30 \%$ and $30 \%$ to $40 \%$ CSP filled epoxy composite is approximately constant.

The maximum flexural strength is obtained for the composite prepared with $30 \%$ CSP filled while; the flexural strength is minimum for the composite prepared with $40 \%$ CSP filled. The flexural strength curve (See Fig. 7) shows that an increase of filler volume flexural strength increases from $20 \%$ to $30 \%$, while, the flexural strength decreases on increasing filler volume from $30 \%$ to $40 \%$. Thus, the rate of decrease of flexural strength from $30 \%$ to $40 \%$ is greater than the rate of increase from $20 \%$ to $30 \%$ CSP filled composite.

The less water absorption is obtained for the composite prepared with $20 \%$ CSP volume fraction (Fig. 8). An increase of reinforcing volume the water absorption goes on increasing.

Consequently, the composite prepared with $20 \%$ to $30 \%$ CSP filled volume fraction is suitable for the application in the interior part of an aircraft, motor car and automobile where materials with good tensile strength, low density and low hydrophilic characteristic are required.

\section{Acknowledgements}

We are gratefully acknowledged to Advanced Centre of Material Science (ACMS) Laboratory, Indian Institute of Technology, Kanpur, INDIA for providing Tensile and Flexural strength testing facilities.

\section{References}

[1] T. Prakash, " Processing and Characterization of Natural Fiber Reinforced Polymer Composites,” Bachelor's Thesis, National Institute of Technology, Rourkela, 2009.

[2] S.Husseniyah, M. Mostapha," The effect of filler content on properties of coconut shell filled polyester composites", Malaysian polymer journal, vol.6, No-1, p 87-97.(2011)

[3] Pradhan, K.S., Dwarkadasa, S.E., Reucroft, J.P.,” Processing and characterization of coconut shell powder filled UHMWPE "Materials science and Engineering A Journal", 367(1-2),pp.57-62.(2004)

[4] Bledzki,A.K. and Gassan, J.."Composite reinforced with cellulose fiber” Prog. Polymer science Journal, 24 (1), pp.221-274. (1999)

[5] Sapuan,S.M., Harimi,M., \& Maleque,M.A.,“ Mechanical properties of Epoxy/coconut shell filler particle composites".The Arabian Journal for science and Enginering28 (2B), pp.171-181. (2003)

[6] Joseph,P.V.,Kuruvilla J,Thomas S.,"Composites science and technology": 59(11): pp.1625-1640.(1999).

[7] Jain,S.,Kumar,R.,Jindal,U.C.”Mechanical behavior of bamboo and bamboo composites," J.Material Science, 27, pp.4598-4604.

[8] Agunsoye J. Olumuyiwa, Talabi S. Issac, Sanni O, Samaual "Study of mechanical behavior of Coconut Shell reinforced Polymer matrix composites", Journal of minerals and materials characterization and Engineering,774-779 (2012).

[9] Han-Seung Yang,Hyun-joong Kim,Hee-Jun Park,Bum-Jae Lee, Taek- Sung Hwang." Water absorption behavior and mechanical properties of lignocellulosic filler-polyolefi bio-composites". Elsevier, composite structures 72, pp.429-437 (2006) 